\title{
Stability after Cleft Maxillary Distraction Osteogenesis or Conventional Orthognathic Surgery
}

\author{
Kristian Andersen ${ }^{1}$, Martin Svenstrup ${ }^{2}$, Thomas Klit Pedersen ${ }^{1}$, Annelise Küseler ${ }^{1}$, John Jensen ${ }^{1}$, \\ Sven Erik Nørholt ${ }^{1}$
}

${ }^{1}$ Department of Maxillofacial Surgery, Aarhus University Hospital, Aarhus, Denmark.

${ }^{2}$ Private practice.

\section{Corresponding Author:}

Kristian Andersen

Department of Oral and Maxillofacial Surgery

Aarhus University Hospital

Nørrebrogade 44, 8000 Århus C, Aarhus

Denmark

Phone: 004589492970

Fax: 004589492930

E-mail: krisae@,rm.dk

\begin{abstract}
Objectives: To compare stability of maxillary advancements in patients with cleft lip and palate following distraction osteogenesis or orthognathic surgery.

Material and Methods: Inclusion criteria: 1) cleft lip and palate, 2) advancement $>8 \mathrm{~mm}$. Eleven patients comprised the distraction osteogenesis group (DOG). Seven patients comprised the orthognathic treatment group (CONVG). Skeletal and soft tissue points were traced on lateral cephalograms: T1 (preoperatively), T2 (after surgery), T3 (follow-up). Group differences were analyzed using Students t-test.

Results: At T1-T2, advancement of $6.98 \mathrm{~mm}(\mathrm{P}=0.002)$ was observed in DOG. Horizontal overjet increased $11.62 \mathrm{~mm}$ $(\mathrm{P}=0.001)$. A point-nasion-B point $(\mathrm{ANB})$ angle increased $8.82^{\circ}(\mathrm{P}=0.001)$. Aesthetic plane to upper lip was reduced 5.44 $\mathrm{mm}(\mathrm{P}=0.017)$ and the naso-labial angle increased $16.6^{\circ}(\mathrm{P}=0.001)$. Vertical overbite $(\mathrm{VOB})$ increased $2.27 \mathrm{~mm}(\mathrm{P}=0.021)$. In T2-T3, no significant changes were observed in DOG. In T1-T2, horizontal overjet increased 8.45 $\mathrm{mm}(\mathrm{P}=0.02)$. The ANB angle, $9.33^{\circ}(\mathrm{P}=0.009)$ in CONVG. At T2-T3, VOB increased, $2.35 \mathrm{~mm}(\mathrm{P}=0.046)$, and the $\mathrm{ANB}$ angle reduced, $3.83^{\circ}(\mathrm{P}=$ 0.003). In T2-T3, no parameters changed in CONVG.

At follow-up (T3), VOB increased in CONVG compared with DOG, $(\mathrm{P}=0.01)$. Vertical position of A point differed between the groups $(\mathrm{P}=0.04)$. No significant intergroup differences between soft tissue parameters occurred.

Conclusions: Distraction osteogenesis resulted in a stable position of the maxilla and movement upwards in vertical plane, however in case of orthognathic treatment sagittal relapse and a continued postoperatively downward movement was registered.
\end{abstract}

Keywords: cleft palate; distraction osteogenesis; orthognathic surgery.

Accepted for publication: 30 January 2015

To cite this article:

Andersen K, Svenstrup M, Pedersen TK, Küseler A, Jensen J, Nørholt SE. Stability after Cleft Maxillary Distraction Osteogenesis or Conventional Orthognathic Surgery.

J Oral Maxillofac Res 2015;6(2):e2

URL: http://www.ejomr.org/JOMR/archives/2015/2/e2/v6n2e2.pdf

doi: $10.5037 /$ jomr.2015.6202 


\section{INTRODUCTION}

Maxillary retrognatism is a common complication in patients with cleft lip and palate (CLP). Often surgical advancement of the maxilla may improve function, occlusion and aesthetics. According to Rachmiel [1] between 25 and $60 \%$ of the CLP-patients need a surgical advancement of the maxilla. Since the 1970s the procedure has treatment modality of choice has been an orthodontic-surgical treatment with a Le Fort I osteotomy often combined with a bone graft [2]. In patients with a large skeletal sagittal discrepancy a mandibular set-back has been included. The long term stability of this treatment has been studied and a considerable tendency towards relapse in the sagittal plane has been observed dependent on the amount of sagittal advancement $[\underline{3}, \underline{4}]$.

The advancement of the maxilla by the use of distraction osteogenesis (DO) results in a gradual formation of bone in the line of osteotomy by the use of traction [5]. Maxillary DO is described as a safe and efficient procedure in patients with CLP $[\underline{6}, \underline{7}]$. A growing body of literature has revealed stable results following maxillary DO in patients with CLP $[\underline{8}, \underline{9}$. However, data has been published from few research centers, indicating a need for validation of the results from more research centers.

The aim of the present study was to compare soft tissue and hard tissue changes and postoperative stability in patients with cleft lip and palate following conventional Le Fort I advancement or maxillary distraction osteogenesis.

\section{MATERIAL AND METHODS}

Forty-two patients diagnosed with maxillary hypoplasia and CLP were treated at Department of Oral and Maxillofacial Surgery, Aarhus University Hospital, Aarhus, Denmark in the period January 1996 - December 2007. The inclusion criteria included: 1) a diagnosis of repaired cleft lip and palate with secondary alveolar bone grafting, 2) maxillary advancement $>8 \mathrm{~mm}$ by the means of orthognathic surgery or distraction osteogenesis. Exclusion criteria included: 1) maxillary osteotomy other than Le Fort I and 2) incomplete records. Of the 17 patients treated with DO 11 patients were included in the study, 7 men and 4 women. The age range was 14 - 23 years at surgery (average 16.3 years). Eight patients were treated with internal distractors and three patients were treated with external distractors. In the period from January 1996 to December 2007, 25 CLP- patients received a conventional orthodontic surgical treatment course. Seven patients met the inclusion criteria for orthognathic treatment group (CONVG): 4 men and 3 women. The age range was $14-20$ years at surgery (average 16.7 years). The study was conducted according to the Helsinki Declaration. The Central Denmark Region Committees on Health Research Ethics approved the study.

\section{Presurgical procedure}

All patients had presurgical orthodontic treatment to gain optimal dento-alveolar relations. All patients were registered for model surgery using face-bow registration, wax bite and articulator mounting. The position of the maxilla was planned in advance after model surgery and indicated with an individual operating splint which in the distraction osteogenesis group (DOG) served as a guide for intermaxillary elastic traction after the active distraction period. Patients planned for treatment with internal distraction devices were CT-scanned and a three-dimensional model of the cranium was produced on which the distraction devices were preoperatively adapted by the surgeon.

\section{Surgical treatment of CONVG}

The conventionally treated patients had a standardized Le Fort I osteotomy according to Bell [10]. The surgical procedure was performed under general anaesthesia after intravenous administration of 2 MIU penicillin. A circumvestibular incision exposed the maxillary bone. Reference lines were marked on the maxilla followed by a Le Fort I osteotomy and the maxilla was down fractured. The maxilla was mobilized, and if indicated bone was removed to allow impaction of the maxilla. A wafer facilitated maxillomandibular fixation, before the sagittal and vertical position of the maxilla was checked and osteosynthesis of the maxilla was performed.

\section{Surgical treatment of DOG}

The surgical procedure was performed under general anaesthesia after intravenous administration of 2 MIU penicillin. A vestibular incision exposing the maxilla was performed. Distraction devices were fixed according to the planned position on the anterior surface of the maxilla and the zygomatic buttress with the guiding splints indicating the planned vector. Three patients had an external halo distraction device placed (Rigid External Device, KLS Martin, USA) and eight patients had internal 
distraction devices (Synthes or KLS Martin, USA). The distraction devices were selected individually on patient-based characteristics. The smallest internal devices were chosen and the lengths were 15 - $25 \mathrm{~mm}$. Two screws on either side of the osteotomy retained the devices while the remaining screw holes were marked. The distraction devices were removed, osteotomies completed, and the maxilla downfractured. The devices were placed according to the screw holes, and the maxilla was advanced to check its mobility and the operation of the devices. The devices were submerged with the activation arm penetrating the vestibular mucosa.

After a latency period of five days, the distraction phase was initiated with two daily activations corresponding to $1 \mathrm{~mm}$ advancement per day until the planned position of the maxilla was achieved. Intermaxillary elastics were used to adjust the position according to the splint. After 12 weeks of consolidation, the distraction devices were removed in general anaesthesia and postsurgical orthodontics completed the treatment.

\section{Cephalometric analysis}

Lateral cephalograms were taken preoperatively (T1),

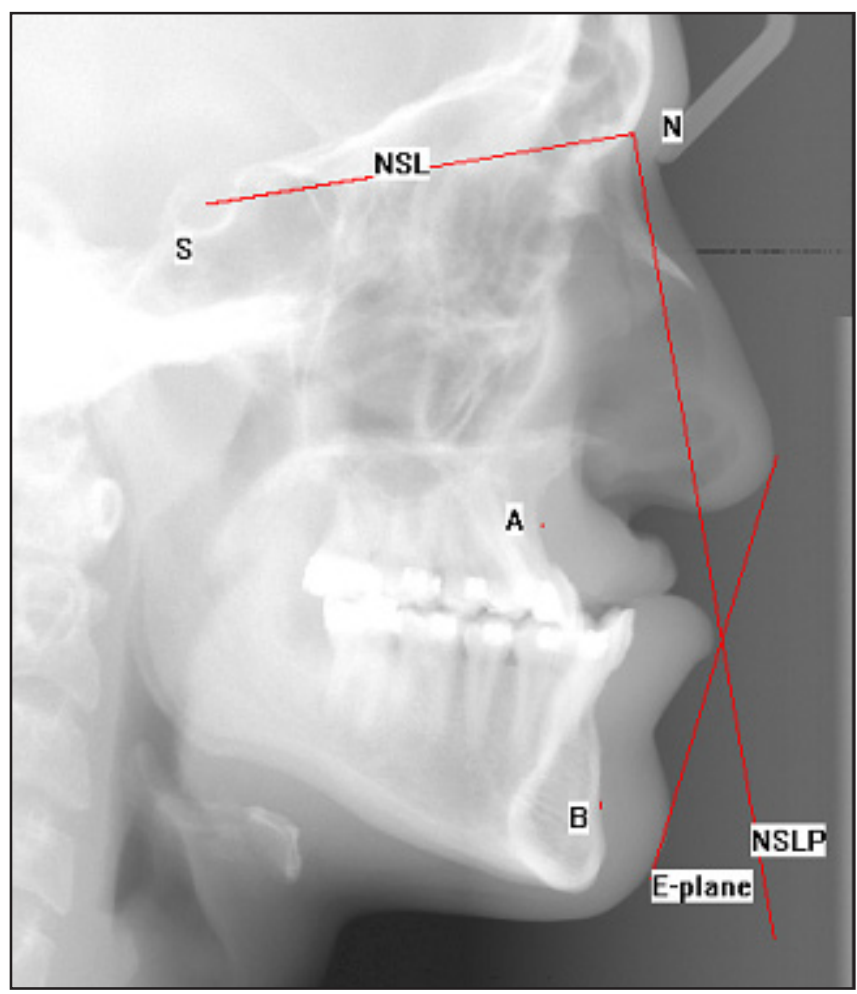

Figure 1. Anatomical landmarks and reference lines used for the cephalometric analysis. $\mathrm{A}=\mathrm{A}$ point, the deepest point on the anterior border of the maxilla; $\mathrm{B}=\mathrm{B}$ point, the deepest point on the anterior border of the mandible; $\mathrm{S}=$ sella; $\mathrm{N}=$ nasion; $\mathrm{NSL}=$ nasion-sella line; NSLP $=$ nasion-sella line perpendicular; E-plane $=$ aesthetic plane. after removal of the distractors in the DOG or at the first control consultation after surgery (T2) in CONVG, and at follow-up (T3) after 9 months (DOG) and 14 months (CONVG).

The lateral cephalograms were analyzed in relation to changes in the skeletal and soft tissue profile. Five anatomically skeletal and two soft tissue points were chosen (Figure 1). The nasion-sella line (NSL), angle between the upper lip and the lower rim of the nose, and the line perpendicular to the nasion-sella line (NSLP), were used as reference lines for the hard tissue, and the aesthetic plane (E-plane), line from the tip of the nose to the most prominent point of the chin, for soft tissue analysis (Figure 1). The following horizontal, vertical and angular measurements were performed: A point to the nasion-sella line perpendicular (A-NSLP), horizontal overjet (HOB), upper lip to E-plane, A point to the nasion-sella line (A-NSL), A pointnasion-B point (ANB) angle and nasolabial angle (NLA) (Figure 2). Also, the horizontal and vertical overbite was measured as the distance from the upper and lower incisal edge horizontally and vertically.

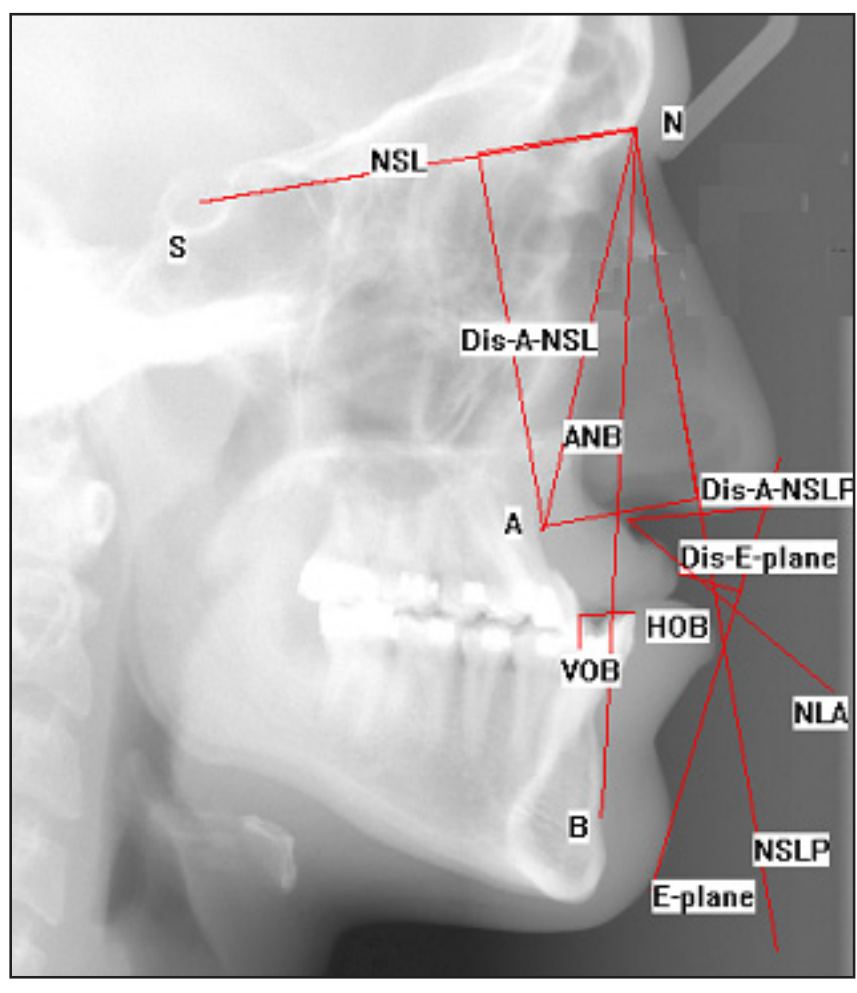

Figure 2. Measured angles and distances on lateral cephalometric. $\mathrm{A}=\mathrm{A}$ point, the deepest point on the anterior border of the maxilla; $\mathrm{B}=\mathrm{B}$ point, the deepest point on the anterior border of the mandible; $\mathrm{S}=$ sella; $\mathrm{N}=$ nasion; $\mathrm{NLA}=$ naso-labial-angle; NSL = nasionsella line; Dis-A-NSL = angular distance subspinale A point to the nasion-sella line; NSLP = nasion-sella line perpendicular; Dis-ANSLP = angular distance subspinale A point to the nasion-sella line perpendicular; $\mathrm{HOB}=$ horizontal overjet; $\mathrm{VOB}=$ vertical overbite; E-plane $=$ aesthetic plane; Dis-E-plane $=$ angular distance from the aesthetic plane to the upper lip. 
A few conventional lateral cephalograms had to be scanned and digitalized. Cephalograms were calibrated and traced in the computer software DimAxis Pro (Planmeca, Helsinki, Finland).

\section{Statistical analysis}

The results of the tracings were analyzed using the software SPSS 15 (IBM, USA). The results were expressed as means and standard deviations (M [SD]). Levene's test revealed homogeneity of variance for Group A and Group B. The intragroup and intergroup differences for the periods T1-T2 and T2-T3 were analyzed. Paired t-tests were used when comparing intragroup differences and unpaired t-tests were used when comparing intergroup differences. Statistical significance was defined as $\mathrm{P}<0.05$. The tracings were performed by one of the authors. Reliability and error analysis tests from the two sets of measurements were performed. Intra-reliability was confirmed by a paired t-test with a 5-percent level of significance and showed no significant differences between the tracings performed at two different occasions by the same investigator. Measurement error was estimated according to Dahlberg's formula and the errors ranged from $0.23 \mathrm{~mm} /$ degrees to $0.94 \mathrm{~mm}$ for the linear measurements [11].

\section{RESULTS \\ Intragroup differences}

Changes at $\mathrm{T} 2$ and $\mathrm{T} 3$ are presented in Table 1 and Table 2. In DOG a significant average advancement of $6.98 \mathrm{~mm}(\mathrm{P}=0.002)$ was observed postoperatively (T1-T2). The horizontal overjet increased $11.62 \mathrm{~mm}$ $(\mathrm{P}=0.001)$ to a normal sagittal incisal relationship and an increase of the ANB angle $8.82^{\circ}(\mathrm{P}=0.001)$

Table 1. Intragroup (DOG) diagnostic parameters changes

\begin{tabular}{|c|c|c|c|c|c|c|c|}
\hline \multirow{3}{*}{ Parameters } & \multicolumn{3}{|c|}{ Mean (SD) } & \multicolumn{2}{|c|}{$\begin{array}{c}\text { Changes as a result of } \\
\text { the treatment }\end{array}$} & \multicolumn{2}{|c|}{$\begin{array}{l}\text { Change } \\
\text { in the follow-up period }\end{array}$} \\
\hline & T1 & T2 & T3 & \multirow{2}{*}{ T1-T2 } & \multirow{2}{*}{ P value } & \multirow{2}{*}{ T2-T3 } & \multirow{2}{*}{ P-value } \\
\hline & $\mathbf{N}=\mathbf{1 1}$ & $\mathbf{N}=\mathbf{1 1}$ & $\mathbf{N}=\mathbf{8}$ & & & & \\
\hline A-NSL (mm) & $57.98(6.22)$ & $63.02(7.56)$ & $60.37(6.72)$ & 5.04 & 0.102 & -3.08 & 0.108 \\
\hline A-NSLP (mm) & $-12.74(10.09)$ & $-5.76(8.07)$ & $-6.79(8.97)$ & 6.98 & $0.002^{\mathrm{a}}$ & -0.75 & 0.758 \\
\hline Horizontal overjet $(\mathrm{mm})$ & $-9.56(2.14)$ & $2.06(2.66)$ & $2.11(0.99)$ & 11.62 & $0^{\mathrm{a}}$ & 0.03 & 0.969 \\
\hline Vertical overbite $(\mathrm{mm})$ & $-0.66(3.46)$ & $1.61(1.59)$ & $1.72(1.9)$ & 2.27 & $0.02^{\mathrm{a}}$ & 0.07 & 0.873 \\
\hline ANB angle (degrees) & $-4.82(3.71)$ & $4(4.6)$ & $2.88(5.08)$ & 8.82 & $0^{\mathrm{a}}$ & -1.75 & 0.122 \\
\hline Nasolabial angle (degrees) & $72.8(14.88)$ & $89.4(12.83)$ & $81.86(18.01)$ & 16.6 & $0.001^{\mathrm{a}}$ & -5.3 & 0.4 \\
\hline E-plane (mm) & $-7.71(5.95)$ & $-2.28(3.08)$ & $-5.01(1.78)$ & 5.44 & $0.017^{\mathrm{a}}$ & -2.69 & 0.061 \\
\hline
\end{tabular}

${ }^{a} \mathrm{P}<0.05$, paired t-test.

$\mathrm{DOG}=$ distraction osteogenesis group; $\mathrm{SD}=$ standard deviation; $\mathrm{T} 1=$ preoperatively, $\mathrm{T} 2=$ after surgery, $\mathrm{T} 3=$ follow-up; $\mathrm{N}=$ number of patients; A-NSL = A point to the nasion-sella line; A-NSLP = A point to the nasion-sella line perpendicular, ANB = A point-nasion-B point; E-plane $=$ aesthetic plane.

Table 2. Intragroup (COVNG) diagnostic parameters changes

\begin{tabular}{|c|c|c|c|c|c|c|c|}
\hline \multirow{3}{*}{ Parameters } & \multicolumn{3}{|c|}{ Mean (SD) } & \multirow{3}{*}{$\begin{array}{c}\text { Changes as a } \\
\text { result of } \\
\text { the treatment }\end{array}$} & \multirow{3}{*}{$\begin{array}{l}\text { Significe } \\
\text { P-value }\end{array}$} & \multirow{3}{*}{$\begin{array}{c}\text { Change } \\
\text { in the follow- } \\
\text { up period } \\
\text { T2-T3 }\end{array}$} & \multirow{3}{*}{$\begin{array}{l}\text { Significe } \\
\text { P-value }\end{array}$} \\
\hline & \multirow{2}{*}{$\begin{array}{c}\mathrm{T} 1 \\
\mathrm{~N}=7\end{array}$} & \multirow{2}{*}{$\begin{array}{c}\text { T2 } \\
N=7\end{array}$} & \multirow{2}{*}{$\begin{array}{c}\text { T3 } \\
\mathrm{N}=7\end{array}$} & & & & \\
\hline & & & & & & & \\
\hline A-NSL (mm) & $52.58(5.97)$ & $55.86(6.13)$ & $59.47(5.39)$ & 3.28 & 0.377 & 3.62 & 0.192 \\
\hline A-NSLP (mm) & $-11.27(7.48)$ & $-6.29(6.88)$ & $-8.47(6.41)$ & 4.98 & 0.217 & -2.19 & 0.282 \\
\hline Horizontal overjet (mm) & $-4.57(5.99)$ & $3.88(1.45)$ & $3.2(1.02)$ & 8.45 & $0.02^{\mathrm{a}}$ & -0.68 & 0.208 \\
\hline Vertical overbite $(\mathrm{mm})$ & $-0.34(4.2)$ & $-0.38(2.55)$ & $1.98(2.09)$ & 0.04 & 0.985 & 2.35 & $0.046^{\mathrm{a}}$ \\
\hline ANB angle (degrees) & $-3.83(3.25)$ & $5.5(2.88)$ & $1.67(2.25)$ & 9.33 & $0.009^{\mathrm{a}}$ & -3.83 & $0.003^{\mathrm{a}}$ \\
\hline Nasolabial angle (degrees) & $64.42(13.7)$ & $59.47(5.39)$ & $61.42(11.48)$ & -4.95 & 0.38 & 1,95 & 0.08 \\
\hline E-plane (mm) & $-7.99(2.52)$ & $-8.47(5.39)$ & $-4.71(3.99)$ & -0.48 & 0.871 & 3.14 & 0.35 \\
\hline
\end{tabular}

${ }^{\text {ap }}<0.05$, paired t-test.

$\mathrm{CONVG}=$ orthognathic treatment group; $\mathrm{SD}=$ standard deviation; $\mathrm{T} 1=$ preoperatively, $\mathrm{T} 2=$ after surgery, $\mathrm{T} 3=$ follow-up; $\mathrm{N}=$ number of patients; A-NSL = A point to the nasion-sella line; A-NSLP = A point to the nasion-sella line perpendicular, ANB = A point-nasion-B point; E-plane $=$ aesthetic plane 
was observed. The distance from the E-plane to the upper lip was reduced $5.44 \mathrm{~mm}(\mathrm{P}=0.017)$ and the naso-labial angle was significantly increased $16.6^{\circ}$ $(\mathrm{P}=0.001)$. An increase on $2.27 \mathrm{~mm}(\mathrm{P}=0.021)$ of the incisal vertical overlap was registered but there was no change of the vertical position of the A point $(\mathrm{P}=0.002)$. No significant changes were observed in the period T2-T3 in the DOG indicating a stable skeletal and dento-alveolar position of the maxilla at follow-up.

In CONVG only a significant increase of the horizontal overjet, $8.45 \mathrm{~mm}(\mathrm{P}=0.02)$ and the ANB angle, $9.33^{\circ}(\mathrm{P}=0.009)$ were observed postoperatively. At follow-up (T3), an increase of the vertical overbite was seen, $2.35 \mathrm{~mm}(\mathrm{P}=0.046)$. A reduction of the ANB angle, $3.83^{\circ}(\mathrm{P}=0.003)$ was observed indicating a relapse towards the preoperative position of the maxilla. T1-T2 indicated a reduction of the nasolabial angle $(\mathrm{P}=0.08)$, and the distance from the upper lip to the E-plane $(\mathrm{P}=0.35)$. In the followup period, T2-T3, no parameters were significantly changed.

\section{Intergroup differences}

At $\mathrm{T} 1$ there was no significant difference between the mean age in the two groups. Presurgically at $\mathrm{T} 1$ no significant differences between DOG and CONVG was registered according to the chosen outcome variables (Table 3). The differences among the groups were not significant when comparing the changes at T2. At follow-up (T3) the vertical position of the A point had increased in CONVG while the same variable was reduced in the DOG whereby the difference between the two groups became significant $(P=0.04)$. Furthermore, the vertical overbite was significantly increased in CONVG compared with DOG, $P=0.01$. No significant intergroup differences existed in relation to the soft tissue parameters.

\section{DISCUSSION}

The present study aimed to compare soft and hard tissue changes and postoperative stability in patients with CLP following conventional Le Fort I advancement or maxillary DO.

Due to a hypoplastic maxilla patients with CLP often require a surgical advancement of the maxilla to normalize facial proportions, occlusion and jaw relations and increase the psychosocial well-being of the patient. As a result of preceding surgical procedures including primary soft tissue closure, abundant scar tissue in relation to the maxilla may make advancement surgery more difficult and increase the risk of relapse postoperatively. DO has previously proven to offer a more stable position of the maxilla than conventional advancement in patients with CLP [12]. As documented in previous studies, the present study indicated stable results following maxillary DO in a group of patients with CLP, hereby adding to the existing knowledge based on the experiences from few centres around the world. Furthermore, the results support the continued clinical use of maxillary DO in patients with a retrognathic maxilla and CLP.

Although DO is a safe and recognized method for advancements of the maxilla there are obvious drawbacks to consider. Once a uni-vectorial internal appliance is positioned the vector of distraction cannot be changed and no rotational adjustments can be done. This can influence the accuracy of the final position of maxilla. In the present study, we were able to compensate for this problem by using intermaxillary elastics postoperatively and a surgical splint to obtain more accurate relations.

The period of active DO and healing of callus has duration of three to four months which can be

Table 3. Intergroup (DOG and CONVG) diagnostic parameter's differences

\begin{tabular}{l|c|c|c|c}
\hline \multicolumn{1}{c|}{ Parameters } & $\begin{array}{c}\text { Differences } \\
\text { DOG - CONVG } \\
\text { T1-T2 (mean) }\end{array}$ & P-value & $\begin{array}{c}\text { Differences } \\
\text { DOG - CONVG } \\
\text { T2-T3 (mean) }\end{array}$ & P-value \\
\hline A-NSL (mm) & 1.76 & 0.7 & 6.7 & $0.04^{\mathrm{a}}$ \\
\hline A-NSLP (mm) & 2 & 0.58 & -1.44 & 0.64 \\
\hline Horizontal overjet (mm) & 3.18 & 0.16 & -0.71 & 0.49 \\
\hline Vertical overbite (mm) & 2.31 & 0.2 & 2.28 & $0.01^{\mathrm{a}}$ \\
\hline ANB angle (degrees) & 0.52 & 0.82 & -2.08 & 0.13 \\
\hline Nasolabial angle (degrees) & -9.1 & 0.18 & -1.38 & 0.85 \\
\hline E-plane (mm) & 0.09 & 0.98 & 0.06 & 0.97 \\
\hline
\end{tabular}

${ }^{a} \mathrm{P}<0.05$, unpaired t-test.

$\mathrm{DOG}=$ distraction osteogenesis group $\mathrm{CONVG}=$ orthognathic treatment group; $\mathrm{T} 1=$ preoperatively, $\mathrm{T} 2=$ after surgery, $\mathrm{T} 3=$ follow-up; $\mathrm{N}=$ number of patients; $\mathrm{A}-\mathrm{NSL}=\mathrm{A}$ point to the nasion-sella line; $\mathrm{A}-\mathrm{NSLP}=\mathrm{A}$ point to the nasion-sella line perpendicular, $\mathrm{ANB}=\mathrm{A}$ pointnasion-B point; E-plane $=$ aesthetic plane. 
a socially, physically and psychologically challenging period for the patient. Furthermore, the DO treatment course necessitates two surgical procedures in general anaesthesia for placement and removal of the distraction devices which is an obvious drawback compared to the conventional treatment necessitating only a single surgical procedure. The conventional advancement treatment may be more extensive and challenging for the patient postoperatively. DO patients are more satisfied with their appearance postoperatively but they are less content with the period wearing the appliances [13].

It has been discussed whether DO presents a method to improve stability $[14,15]$. The present study demonstrates that no significant relapse occurred in the follow-up period in spite of a large advancement of the position of the maxilla in DOG. The obtained advancement was significantly larger in DOG compared to CONVG, whereas the relapse of the vertical overlap was significantly larger in the latter. There was a significant difference in the change of the vertical position of the A point in the two groups at T3 indicating a relapse in the CONVG. Both treatment procedures resulted in a vertical downward movement of the maxilla, but at follow-up the maxilla had moved in two different directions. CONVG experienced a continued vertical downward movement of the maxilla while the DOG experienced a vertical upward movement of the maxilla equivalent to a relapse towards the preoperative position. The use of elastic traction during the presurgical orthodontics may have caused the continued downward movement of the maxilla in the CONVG.

At follow-up the mean horizontal and vertical relapses were $0.8 \mathrm{~mm}$ and $3.1 \mathrm{~mm}$, respectively, corresponding to a $10 \%$ and $61 \%$ relapse. Kanno et al. [14] reported a horizontal relapse of $8 \%$ and a vertical relapse of $19 \%$ after DO. Chua et al. [ $[$ ] reported a postoperatively continued advancement and lengthening of the maxilla after DO, arguing the importance of using elastic traction to control the callus formation. These three recent studies indicate the possibility of obtaining a stable position of the maxilla in the horizontal plane. In our study a considerable relapse of the maxilla in the vertical plane was observed after DO. The reason for this finding could be inadequate use of elastic traction postoperatively.

Due to limitations of the present study, e.g. the retrospective design of the present study, different distraction devices and inclusion of few patients, the results need to be interpreted with caution. However, the results add to a growing body of literature indicating stable results following maxillary DO.

The present study indicates that maxillary DO in patients with CLP offers stable and aesthetically good results and therefore is the method of choice in moderate to large advancements of the maxilla.

\section{CONCLUSIONS}

Distraction osteogenesis results in a stable position of the maxilla. Conventional orthognathic treatment resulted in a sagittal relapse and a continued postoperatively downward movement of the maxilla. The analysis showed significant differences in the vertical postoperative movement of the maxilla. In the distraction osteogenesis group it moved upwards and in the conventional orthognathic treatment group downwards.

\section{ACKNOWLEDGMENTS AND DISCLOSURE STATEMENTS}

The authors report no conflicts of interest related to this study.

\section{REFERENCES}

1. Rachmiel A. Treatment of maxillary cleft palate: distraction osteogenesis versus orthognathic surgery--part one: Maxillary distraction. J Oral Maxillofac Surg. 2007 Apr;65(4):753-7. [Medline: 17368374] [doi: 10.1016/j.joms.2006.08.010]

2. Houston WJ, James DR, Jones E, Kavvadia S. Le Fort I maxillary osteotomies in cleft palate cases. Surgical changes and stability. J Craniomaxillofac Surg. 1989 Jan;17(1):9-15. Review. [Medline: 2644310] [doi: $10.1016 / \mathrm{S} 1010-5182(89) 80121-0]$

3. Hirano A, Suzuki H. Factors related to relapse after Le Fort I maxillary advancement osteotomy in patients with cleft lip and palate. Cleft Palate Craniofac J. 2001 Jan;38(1):1-10. [Medline: 11204674] [doi: 10.1597/1545-1569(2001)0382.0.CO;2]

4. Erbe M, Stoelinga PJ, Leenen RJ. Long-term results of segmental repositioning of the maxilla in cleft palate patients without previously grafted alveolo-palatal clefts. J Craniomaxillofac Surg. 1996 Apr;24(2):109-17. [Medline: 8773893] [doi: 10.1016/S1010-5182(96)80022-9]

5. Pereira MA, Luiz de Freitas PH, da Rosa TF, Xavier CB. Understanding distraction osteogenesis on the maxillofacial complex: a literature review. J Oral Maxillofac Surg. 2007 Dec;65(12):2518-23. [Medline: 18022479] [doi: 10.1016/j.joms.2006.10.019] 
6. Rachmiel A, Aizenbud D, Peled M. Long-term results in maxillary deficiency using intraoral devices. Int J Oral Maxillofac Surg. 2005 Jul;34(5):473-9. [Medline: 16053864] [doi: 10.1016/j.ijom.2005.01.004]

7. Figueroa AA, Polley JW, Friede H, Ko EW. Long-term skeletal stability after maxillary advancement with distraction osteogenesis using a rigid external distraction device in cleft maxillary deformities. Plast Reconstr Surg. 2004 Nov;114(6):1382-92; discussion 1393-4. [Medline: 15509923] [doi: 10.1097/01.PRS.0000138593.89303.1B]

8. Chua HD, Hägg MB, Cheung LK. Cleft maxillary distraction versus orthognathic surgery--which one is more stable in 5 years? Oral Surg Oral Med Oral Pathol Oral Radiol Endod. 2010 Jun;109(6):803-14. [Medline: 20299247] [doi: 10.1016/j.tripleo.2009.10.056]

9. Saltaji H, Major MP, Altalibi M, Youssef M, Flores-Mir C. Long-term skeletal stability after maxillary advancement with distraction osteogenesis in cleft lip and palate patients. Angle Orthod. 2012 Nov;82(6):1115-22. [Medline: 22506512] [doi: 10.2319/011212-27.1]

10. Bell WH. Le Forte I osteotomy for correction of maxillary deformities. J Oral Surg. 1975 Jun;33(6):412-26. [Medline: 1055202]

11. Houston WJ. The analysis of errors in orthodontic measurements. Am J Orthod. 1983 May;83(5):382-90. [Medline: 6573846] [doi: 10.1016/0002-9416(83)90322-6]

12. Cheung LK, Chua HD, Hägg MB. Cleft maxillary distraction versus orthognathic surgery: clinical morbidities and surgical relapse. Plast Reconstr Surg. 2006 Sep 15;118(4):996-1008; discussion 1009. [Medline: 16980862] [doi: 10.1097/01.prs.0000232358.31321.ea]

13. Andersen K, Nørholt SE, Küseler A, Jensen J, Pedersen TK. A Retrospective Study of Cleft lip and palate Patients' Satisfaction after Maxillary Distraction or Traditional Advancement of the Maxilla. J Oral Maxillofac Res. 2012 Jul 1;3(2):e3. [URL: http://www.ejomr.org/JOMR/archives/2012/2/e3/v3n2e3ht.htm] [Medline: 24422010] [PMC free article: 3886103] [doi: 10.5037/jomr.2012.3203]

14. Kanno T, Mitsugi M, Hosoe M, Sukegawa S, Yamauchi K, Furuki Y. Long-term skeletal stability after maxillary advancement with distraction osteogenesis in nongrowing patients. J Oral Maxillofac Surg. 2008 Sep;66(9):1833-46. [Medline: 18718390] [doi: 10.1016/j.joms.2007.10.013]

15. Baek SH, Lee JK, Lee JH, Kim MJ, Kim JR. Comparison of treatment outcome and stability between distraction osteogenesis and LeFort I osteotomy in cleft patients with maxillary hypoplasia. J Craniofac Surg. 2007 Sep;18(5):120915. [Medline: 17912117] [doi: $10.1097 /$ scs.0b013e31814b2b8c]

\section{To cite this article:}

Andersen K, Svenstrup M, Pedersen TK, Küseler A, Jensen J, Nørholt SE. Stability after Cleft Maxillary Distraction Osteogenesis or Conventional Orthognathic Surgery.

J Oral Maxillofac Res 2015;6(2):e2

URL: http://www.ejomr.org/JOMR/archives/2015/2/e2/v6n2e2.pdf

doi: $10.5037 /$ jomr.2015.6202

Copyright $\odot$ Andersen K, Svenstrup M, Pedersen TK, Küseler A, Jensen J, Nørholt SE. Published in the JOURNAL OF ORAL \& MAXILLOFACIAL RESEARCH (http://www.ejomr.org), 30 June 2015.

This is an open-access article, first published in the JOURNAL OF ORAL \& MAXILLOFACIAL RESEARCH, distributed under the terms of the Creative Commons Attribution-Noncommercial-No Derivative Works 3.0 Unported License, which permits unrestricted non-commercial use, distribution, and reproduction in any medium, provided the original work and is properly cited. The copyright, license information and link to the original publication on (http://www.ejomr.org) must be included. 